\title{
Depression and Life Quality in Chronic Renal Failure Patients with Polyneuropathy on Hemodialysis
}

\author{
Do Yub Ku, M.D., Young Sook Park, M.D., Hyun Jung Chang, M.D., \\ Sung Rok Kim, M.D. ${ }^{1}$, Jeoung Whan Ryu, M.D. ${ }^{2}$, Woo Jin Kim, M.D.
}

Departments of Physical Medicine and Rehabilitation, ${ }^{1}$ Nephrology and ${ }^{2}$ Neuropsychiatry, Samsung Changwon Hospital, Sungkyunkwan University School of Medicine, Changwon 630-522, ${ }^{3}$ Departments of Physical Medicine and Rehabilitation, Haeundae Paik Hospital, Inje University School of Medicine, Busan 612-862, Korea

\begin{abstract}
Objective To investigate the relationship between severity of peripheral polyneuropathy (PPN) and degree of depression and quality of life in chronic renal failure (CRF) patients on hemodialysis (HD).

Method Forty seven chronic renal failure patients on hemodialysis were recruited (22 male, 25 female, mean age of $63.17 \pm 12.52$ ) and etiology, disease duration, hemodialysis duration, creatinine and hemoglobin were recorded. Motor and sensory nerve conduction studies were carried out on bilateral median, ulnar, tibial and peroneal nerves for diagnosis of polyneuropathy according to our laboratory criteria. The Korean version of Beck depression inventory (BDI) questionnaire translated into Korean for diagnosis of depression, and Korean version of Short Form 36 health survey (SF-36) questionnaire for measurement of general health level were measured in those diagnosed with uremic PPN.

Results Out of 52 patients, 47 were diagnosed with polyneuropathy and mean score for BDI was 18.49 \pm 9.18 . Mean scores for each of Mental Component Summary (MCS) and Physical Component Summary (PCS) of SF-36 were $50.84 \pm 15.42$ and $47.41 \pm 18.68$. The correlation between the scores and polyneuropathy were analyzed by Pearson coefficient. The MCS score was the significant $(\mathrm{p}<0.05)$ correlation parameter with depression $(\mathrm{R}=-0.635)$ and the PCS score was the only parameter with a significant $(\mathrm{p}<0.05)$ correlation with polyneuropathy $(\mathrm{R}=-0.340)$.

Conclusion Uremic polyneuropathy is commonly observed in chronic renal failure patients on hemodialysis. Depression in CRF with uremic PPN is affected by psychological factors other than the PPN itself.
\end{abstract}

Key Words Neuropathy, Chronic renal failure, Depression, Quality of life

Received July 28, 2011; Accepted August 28, 2012

Corresponding author: Young Sook Park

Departments of Physical Medicine and Rehabilitation, Samsung Changwon Hospital, Sungkyunkwan University School of Medicine, 50 Hapsungdong, Masanhoewon-gu, Changwon 630-522, Korea

Tel: +82-55-290-6390, Fax: +82-55-290-6588, E-mail: jijibaeheiwon@hanmail.net

@ This is an open-access article distributed under the terms of the Creative Commons Attribution Non-Commercial License (http://creativecommons. org/licenses/by-nc/3.0) which permits unrestricted noncommercial use, distribution, and reproduction in any medium, provided the original work is properly cited.

Copyright $\odot 2012$ by Korean Academy of Rehabilitation Medicine 


\section{INTRODUCTION}

Patients with chronic renal failure suffer clinical symptoms such as anemia, uremia, hypertension, anorexia and pruritis stemming from poor renal functions that are important in metabolism and endocrine functions giving rise to metabolic, hormonal disorders and electrolyte imbalance. ${ }^{1}$ Uremic peripheral neuropathy, initially described by Hegstrom in 1962, is a common complication in patients who have received hemodialysis over one to two years and the prevalence has been reported to be generally from 60 to $75 \%{ }^{2,3}$ Primary axonal degeneration and secondary demyelination have been reported in pathologic aspect by Asbury et al. ${ }^{4}$ and Dyck et al. ${ }^{5}$ and parathyroid hormone, myoinositol, Beta 2 microglobulin have been suggested as uremic elements causing peripheral neuropathy, although no direct evidence exists. Uremic peripheral neuropathy causes motor disorders including restless legs, cramp and muscular weakness, and sensory disorders including dysesthesia, burning pain, numbness, and autonomic disorders like dizziness, orthostatic hypotension, dyshidrosis, erectile dysfunction, sphincter dysfunction and gastrointestinal dysfunctions. ${ }^{6}$ Such changes can be diagnosed by a questionnaire for the clinical symptoms and electrophysiologic examinations including sympathetic skin response, somatosensory evoked potential study, vibration perception threshold and nerve conduction study. However, the sensitivity and specificity of these tests were variable reported depending on the method, although the nerve conduction study had the highest specificity.

In addition, patients with chronic renal failure are exposed to severe chronic stress as they require a long period of treatment, with no permanent cure and discontinuation of treatments is life-threatening. The resultant depression and anxiety are frequent psychiatric problems and depression has been reported in $20-30 \%$ of patients. ${ }^{7}$ Depression is related to increased morbidity and mortality by treatment refusal, diet therapy inducing malnutrition, increased inflammatory response and decreased immunity. ${ }^{8}$ Despite numerous reports and studies of the relationship between depression and cognitive function, suicidal risk, and quality of life, research on the association between these problems and peripheral polyneuropathy (PPN) in chronic renal failure (CRF) is limited. Thus the purpose of this study is to investigate the relationship between the severity of PPN in CRF on hemodialysis (HD) and depression and quality of life.

\section{MATERIALS AND METHODS}

\section{Participants}

Between November 2010 and April 2011, 115 CRF patients receiving hemodialysis (3-4 hours, 1-4 times per week) at our hospital were recruited from the outpatient clinic. The exclusion criteria were (1) lack of understanding from cognitive dysfunction, (2) past history of CNS or PNS disorder, (3) severe somatic disease except CRF or (4) objection against this study. After exclusions, 47 patients ( 25 men, 22 women), age ranging from 33 to 87 years (mean $63.17 \pm 12.52$ ), were recruited into the study. Body mass index (BMI; $\mathrm{kg} / \mathrm{m}^{2}$ ) ranged from 14.53 to 29.05 (Mean: 22.39 \pm 3.23 ). The Institutional Review Board approved the study, and all participants signed informed consent and research authorized forms.

\section{Study design}

All participants were evaluated for routine blood tests for screening. Nerve conduction studies were performed in our lab. The battery of Beck Depression Inventory and Short Form 36 health survey tests were filled out by the patients.

The results are listed in Table 1. The evaluation methods are as follows:

Nerve conduction studies: Motor and sensory NCS on bilateral median, ulnar, peroneal and tibial nerves as well as F-wave and H-reflex study were performed Viking IV $^{\circledR}$ (Nicolet, Wisconsin, USA). Studies of the sensory nerves were performed antidromically. Sensory and motor latencies were measured at the onset of the negative deflection of the evoked responses. SNAP amplitudes were measured peak-to-peak and CMAP amplitudes were measured from the baseline to the negative peak. The severity of peripheral neuropathy is designated mild, moderate, and severe state according to the criteria of the Department of Physical Medicine and Rehabilitation of Korea University (Table 2).

Beck depression inventory (BDI): Depression was evaluated using the Korean version of Beck Depression Inventory, which is composed of 21 questions, each designed to assess a specific symptom common among those with depression. Each item was scored on a scale 
Table 1. Demographic, Clinical, and Laboratory Data of Chronic Renal Failure Patients

\begin{tabular}{|c|c|c|}
\hline Variables & & Frequency (\%) \\
\hline \multirow[t]{2}{*}{ Gender } & Male & $25(53)$ \\
\hline & Female & $22(47)$ \\
\hline \multirow[t]{6}{*}{ Age } & Mean: $63.17 \pm 12.52$ & \\
\hline & $\leq 50$ & $8(17)$ \\
\hline & 51 to 60 & $10(21)$ \\
\hline & 61 to 70 & $16(34)$ \\
\hline & 71 to 80 & $11(23)$ \\
\hline & $\geq 80$ & $2(4)$ \\
\hline \multirow[t]{3}{*}{ Creatinine (Serum-mg/dl) } & Mean: $6.68 \pm 3.41$ & \\
\hline & Normal (1.3 to 1.5$)$ & $0(0)$ \\
\hline & High $(>1.5)$ & $47(100)$ \\
\hline Hemoglobin (g/dl) & Mean: $10.26 \pm 1.19$ & \\
\hline Albumin (g/dl) & Mean: $3.25 \pm 0.95$ & \\
\hline Body mass index (BMI; $\mathrm{kg} / \mathrm{m}^{2}$ ) & Mean: $22.39 \pm 3.23$ & \\
\hline Uric acid (mg/dl) & Mean: $8.34 \pm 8.90$ & \\
\hline Duration of dialysis (month) & Mean: $6.38 \pm 6.82$ & \\
\hline \multirow[t]{3}{*}{ Education } & $<12$ th grade level & $22(47)$ \\
\hline & High school graduate level & $17(36)$ \\
\hline & College level & $8(17)$ \\
\hline \multirow[t]{4}{*}{ Number of comorbidities } & 0 & $3(6)$ \\
\hline & 1 & $20(43)$ \\
\hline & 2 & $16(34)$ \\
\hline & $>3$ & $8(17)$ \\
\hline \multirow[t]{5}{*}{ Depression (BDI) } & Mean: $18.49 \pm 9.18$ & \\
\hline & Minimal (0 to 13$)$ & $13(28)$ \\
\hline & Mild (14 to 19$)$ & $17(36)$ \\
\hline & Moderate (20 to 28 ) & $7(15)$ \\
\hline & Severe (29 to 63 ) & $10(21)$ \\
\hline Quality of life & Mean & \\
\hline MCS & $50.84 \pm 15.42$ & \\
\hline PCS & $47.41 \pm 18.68$ & \\
\hline \multirow[t]{4}{*}{ Polyneuropathy } & Normal & $5(11)$ \\
\hline & Mild & $19(40)$ \\
\hline & Moderate & $12(25)$ \\
\hline & Severe & $11(23)$ \\
\hline
\end{tabular}

value of 0 to 3 , with total score of 63 . Scores from 0 to 13 represented minimal depressive symptoms, 14 to 19 indicated mild depression, 20 to 28 indicated moderate depression, and 29 to 63 indicated severe depression.

Short form 36 health survey (SF-36): The SF-36 is a multi-purpose, short-form health survey with 36 questions. It measures eight concepts: 1 ) physical functioning,
2) role limitations due to physical health, 3) bodily pain, 4) general health perceptions, 5) vitality, 6) social functioning, 7) role limitation due to emotional problems, and 8) general mental health. These eight concepts divide into 35 subgroups and 1 subgroup of health change. The scores of all subgroups add up to zero to 100 . Zero score is the worst, while 100 score is the best. The two summary 
Table 2. Diagnostic Criteria of Peripheral Polyneuropathy

\begin{tabular}{|c|c|}
\hline 1. Sural SNAP amplitude & $\leq 5 \mu \mathrm{V}$ \\
\hline 2. Median SNAP amplitude & $\leq 10 \mu \mathrm{V}$ \\
\hline 3. Peroneal CMAP amplitude & $\leq 1 \mathrm{mV}$ \\
\hline 4. Peroneal motor velocity & $\begin{array}{l}\text { Distal latency } \geq 6 \mathrm{~ms} \text { or } \\
\mathrm{NCV}<40 \mathrm{~m} / \mathrm{s}\end{array}$ \\
\hline 5. Peroneal F latency & Absent or $>55 \mathrm{~ms}$ \\
\hline 6. Median \& ulnar F latency & Absent or $>35 \mathrm{~ms}$ \\
\hline 7. Tibial F latency & Absent or $>55 \mathrm{~ms}$ \\
\hline 8. $\mathrm{H}$ reflex & Absent or $>35 \mathrm{~ms}$ \\
\hline
\end{tabular}

Mild: Sural $\geq 5 \mu \mathrm{V}$, but at least two, Moderate: Sural plus two to four, Severe: Moderate plus more than three, SNAP: Sensory nerve action potential, CMAP: Compound motor action potential

scores of the physical component and the mental component of Korean version of SF-36 were used.

\section{Statistical analysis}

All analyses were performed using SPSS, version 18.0 (SPSS, Inc, an IBM Company, Chicago, USA). Pearson correlation analysis was used to measure correlation between age, creatinine, hemoglobin, albumin, Body Mass Index (BMI), uric acid, HD duration, education level, concomitant disease, depression and quality of life. Null hypotheses of no difference were rejected if $p$-values were less than 0.05. Significant difference between age, depression, quality of life and severity of peripheral polyneuropathy were measured using Pearson correlation test.

\section{RESULTS}

Five out of 47 CRF patients had normal findings while 42 patients were diagnosed with PPN. Nineteen patients were mild degree, 12 moderate degree patients, and 11 severe degree patients. From the SF-36 questionnaire on quality of life, the mean PCS and MCS of SF-36 were $47.41 \pm 18.68$ and $50.84 \pm 15.42$, respectively, without significant difference. Mean BDI scores on depression was $18.49 \pm 9.18$, with 13 patients with minimal degree (0-13), 17 with mild degree (14-19), 7 with moderate degree (2028 ), and 10 with severe degree (29-63) scores. Correlation among these variables including demographic characteristics of age, gender, BMI, education status, hematologic factors such as creatine, hemoglobin, albumin, uric acid, accompanying diseases, depression and life quality was
Table 3. Correlation between the Depression, Quality of Life, Age and Polyneuropathy Severity

\begin{tabular}{lcc}
\hline \multicolumn{1}{c}{ Pairs of variables } & $\begin{array}{c}\text { Pearson's } \\
\text { R }\end{array}$ & $\begin{array}{c}\text { p-level } \\
\text { (Pearson's } \\
\text { correlation) }\end{array}$ \\
\hline Depression/polyneuropathy & 0.087 & 0.563 \\
PCS/polyneuropathy & -0.340 & $0.019 *$ \\
MCS/polyneuropathy & -0.047 & 0.751 \\
Age/polyneuropathy & -0.109 & 0.464 \\
\hline
\end{tabular}

PCS: Physical component summary of short form 36 health survey (SF-36), MCS: Mental component summary of short form 36 health survey (SF-36)

*Significant at $<0.05$

estimated by Pearson correlation. A weak inverse correlation of $-0.302,-0.321$ were observed when the physical component summary was compared with dialysis duration and education $(\mathrm{p}<0.05)$. Correlation between severity of PPN and age, depression, quality of life was analyzed by Pearson correlation test (Table 3 ). Severity of polyneuropathy was weakly but significantly $(\mathrm{p}<0.05)$ correlated with the physical component summary.

\section{DISCUSSION}

Uremic polyneuropathy is peripheral polyneuropathy combined with autonomic neuropathy in CRF patients. Mitz et al. ${ }^{9}$ reported severity of polyneuropathy was worse when due to diabetes mellitus than in primary renal disease such as nephritis. In a study by Nowichi et al., ${ }^{6}$ the prevalence of autonomic neuropathy in CRF was $46 \%$ in those with DM and $18 \%$ without it, respectively. In the present study, the prevalence of PPN in CRF was $61 \%$ of in those with DM and $27 \%$ without it, but the patients with PPN diagnosed by NCS were categorized according to severity, and we hypothesized that instead of the causative disease, the PPN itself relates to depression and decreased quality of life in CRF patients. Electrophysiologic methods such as sympathetic skin response, somatosensory evoked potential study, vibration perception threshold were not carried out for the current study because their specificity for diagnosis of polyneuropathy was not proved in previous studies. ${ }^{10,11}$ Despite overall negative effects of both physical and psychological signs and symptoms including pain, dyspnea, fatigue, anxiety, anorexia, depression, loss of well-being on quality of life in CRF patients on hemodialysis by Davision and Jhan- 
$\mathrm{gri}^{12}{ }^{12}$ the authors reported depression and anxiety was correlated $(\mathrm{r}=-0.487)$ with the mental component summary while dyspnea was correlated ( $\mathrm{r}=-0.446)$ with the physical component summary of quality of life. Investigation of the associations among quality of life and age, gender, BMI, educational status, creatinine, hemoglobin, albumin, uric acid, duration of dialysis, accompanying diseases using Pearson's correlation showed no significant correlation. With exception of weak inverse correlation between dialysis duration and education and physical component summary $(-0.302,-0.321)$, no correlation was observed with quality of life and depression. The result shows correlation at -0.635 between depression and psychological domain of life quality, higher than that seen by Davision and Jhangri, ${ }^{12}$ but lower than the correlation of 0.77 observed by Chen et al. ${ }^{13}$ in which depression and suicidal attempt was compared in CRF patients. Hong et al. ${ }^{14}$ discovered a higher prevalence of depression in chronic disorders including chronic renal failure by investigating psychological factors according to illness duration in medical patients. Di Matteo et al. ${ }^{15}$ hypothesized that affective disorders such as depression may induce loss of positive expectation and belief in treatment, thus leading to discontinuation of treatment. The patients may be isolated from the society and lose social support, together with cognitive dysfunction causing poor cooperation with the management recommendations. Agganis et al. ${ }^{16}$ demonstrated negative effect of depression on performance speed and executive function related to cognitive function in CRF patients on hemodialysis. Griva et al. ${ }^{17}$ reported cognitive dysfunction to be an independent factor leading to death in CRF patients. Therefore, active intervention in diagnosing and treating depression in CRF patients plays an important role in terms of quality of life. Clinically, diagnosis of depression is made based on the physician's subjective judgment rather than standardized tools, resulting in occasional inaccurate or false diagnosis. Early diagnosis of depression using an objective tool is necessary and should be followed by adequate treatment. ${ }^{18}$ In the present study we used the Korean version of the Beck depression inventory (BDI) scale for evaluation of depressive state and Short Form 36 health survey (SF-36), a comprehensive multifactorial questionnaire that measures generalized health level, which is comprised of 36 items, for evaluation of quality of life. In several studies on CRF patients, sum of the physical and mental component scores effectively analyzed the results and was not significantly different from results by calculating each of 8 low grade scores. ${ }^{19}$ Lee et al. ${ }^{20}$ reported that the treatment with antidepressive medications brings about improvement in depression as well as nutritional status. Thus, due to the high prevalence of depression in CRF patients, early diagnosis and treatment are important for predicting prognosis. This is the first study in the literature to show a relationship between polyneuropathy in CRF patients and quality of life, as well as correlating its severity with depression and quality of life. Contrary to the authors' hypothesis that severity of polyneuropathy would relate to depression, the results demonstrated that polyneuropathy does not correlate with age, depression nor mental component of quality of life. Worsening degree of polyneuropathy impacted the physical component index of life quality only to a small degree. Our results resemble that of Jurice, ${ }^{3}$ in which worsening of electrophysiologic findings with time were observed without uremic PPN. Changes in clinical symptoms in the study on clinical course of CRF patients with uremia also stated that polyneuropathy is more severe in elderly in comparison to younger CRF patients. Our findings contradict this statement by showing insignificant correlation between age and severity. On the other hand, Andrade et al. ${ }^{21}$ categorized chronic renal failure patients into 5 grades of the Kidney Disease Outcome Quality Initiative (NKF-DOQI), depending on severity by correlation between each grade with depression, which showed no significant difference except for increased prevalence of depression in females (17.9\%), low income $(54.2 \%)$ and living with friends or relatives (41.2\%). In other words, neurophysiological changes due to severity of peripheral polyneuropathy do not correlate with depression. In summary, hemodynamic factors affecting physical component summary and neurophysiological factors are not related to depression, and only the Mental Component Summary of SF-36 is related to depression.

\section{CONCLUSION}

We investigated the relationship between the severity of peripheral polyneuropathy and degree of depression and quality of life in chronic renal failure patients on hemodialysis. The severity of polyneuropathy is not correlated with depression and mental component of quality of life while weakly correlated with the physical component of the SF-36. Thus we can conclude that depression in 
chronic renal failure patients is affected by psychological factors rather than the physical factors or severity of neuropathy.

\section{REFERENCES}

1. Braunwald E, Fauci AS, Kasper DL, Hauser SL, Longo DL, Jameson JL. Harrison's principles of inernal medicine, 15th ed, New York: The McGraw-Hill Companies, 2011, 1551-1567

2. Hegstrom RM, Murray JS, Pendras JP, Burnell JM, Scribner BH. Two year's experience with periodic hemidialysis in the treatment of chronic uremia. Trans Am Soc Artif Intern Organs 1962; 8: 266-280

3. Jurice D, Bilic A, Schwarz D, Orsanic D, Gabric M, Spoljaric L, Mihanovic M. Clinical Course of uremic neuropathy in long-term hemodialysis. Coll Antropol 2008; 32: 771-775

4. Asbury AK, Victor M, Adams RD. Uremic polyneuropathy. Arch Neurol 1963; 8: 413-428

5. Dyck PJ, Johnson WJ, Lambert EH, O'Brien PC. Segmental demyelination secondary to axonal degeneration in uremic neuropathy. Mayo Clin Proc 1971; 46: 400-431

6. Nowicki M, Zwiech R, Dryja P, Sobanski W. Autonomic neuropathy in hemodialysis patients: questionnaires versus clinical tests. Clin Exp Nephrol 2009; 13: 152-155

7. Chang JS, Chang EJ, Jung CH. The factors affecting ganeral coping styles in chronic renal failure patients. J Korean Neuropsychiatr Assoc 2003; 42: 396-402

8. Park HC, Yoon HB, Son MJ, Jung ES, Joo KW, Chin HJ, Oh KH, Lim CS, Kim YS, Ahn C, et al. Depression and health-related quality of life in maintenance hemodialysis patients. Clin Nephrol 2010; 73: 374-380

9. Mitz M, Di Benedetto M, Kilingbeil GE, Melvin JL, Piering W. Neuropathy in end-stage renal disease sedcondary to primary renal disease and diabetes. Arch Phys Med Rehabil 1984; 65: 235-238

10. Shin HS, Yoon CH, Yeum HC, Kim HG, Kang NH. The usefulness of sympathetic skin response in patients with chronic renal failure. J Korean Acad Rehab Med 2000; 24: 1129-1135

11. Cho JH, Kwon YW, Ahn JH, Lee JH, Kim SB. Somatosensory evoked potential study in patients with polyneuropathy with chronic renal failure. J Korean Acad
Rehab Med 1997; 21: 553-557

12. Davision SN, Jhangri GS. Impact of pain and symptom burden on the health-related quality of life of hemodialysis patients. J Pain Symtom Manage 2010; 39: 477485

13. Chen CK, Tsai YC, Hsu HJ, Wu IW, Sun CY, Chou CC, Lee CC, Tsai CR, Wu MS, Wang LJ. Depression and suicide risk in hemodialysis patients with chronic renal failure. Psychosomatics 2010; 51: 528

14. Hong YJ, Ock JH, Kong JM, Kim YG, Kim JG. A Comparative study concerning the psychopathologies between the patients with chronic renal failure and those with chronic hepatitis: focused on Medically-ill outpatients compared with. J Korean Neuropsychiatr Assoc 2002; 41: 486-497

15. Di Matteo MR, Lepper HS, Croghan TW. Depression is a risk factor for noncompliance with medical treatment: meta-analysis of effects of anxiety and depression on patient adherence. Arch Intern Med 2000; 160: 2101-2107

16. Agganis BT, Weiner DE, Giang LM, Scott T, Tighiouart H, Griffith JL, Sarnak MJ. Depression and cognitive function in maintenance hemodialysis patients. Am J Kidney Dis 2010; 56: 704-712

17. Griva K, Stygall J, Hankins M, Davenport A, Harrison M, Newman SP. Cognitive impairment and 7-year mortality in dialysis patients. Am J Kidney Dis 2010; 56: 693-703

18. Kim DH, Kim TH, Kim JL, Lee H, Kim SA, Oh KY. Screening test for depression using the SF-36 health survey in patients with chronic musculoskeletal pain. J Korean Acad Rehab Med 2007; 31: 434-439

19. Park JI, Kim SJ, Jung HH, Lee JH. The association of nocturnal sleep pattern with the quality of life in chronic renal failure patients on hemodialysis. J Korean Neuropsychiatr Assoc 2006; 45: 145-151

20. Lee TB, Han $\mathrm{CH}$, Son BK. The preliminary study of the effects of antidepressant treatment on the depressive symptoms and the nutritional indexes in the patients with chronic renal failure on maintenance hemodialysis. J Korean Neuropsychiatr Assoc 2000; 39: 11021110

21. Andrade CP, Cruz MC, Urrutia M, Pereira O, Draibe SA, Nogueira-Martins LA, Sesso R. Evaluation of depressive symptoms in patients with chronic renal failure. J Nephrol 2010; 23: 168-174 